\title{
The management of pregnancy in hypertensive patients
}

\author{
R.D.G. Tunbridge \\ Department of Medicine, Manchester Royal Infirmary, Manchester M13 9WL, UK
}

\section{Introduction}

Social Trends reported that the average age of married primigravida in the UK has risen to 27.8 , the highest ever recorded. ${ }^{1}$ The opportunity for recognizing hypertension and initiating preconception counselling before the first pregnancy has therefore increased. This review primarily addresses the management of women known to be hypertensive before conception, a group classified as chronic hypertension and chronic renal disease diagnosed before, during or persisting after pregnancy. ${ }^{2}$

\section{Preconception counselling for hypertensive patients}

The confidential enquiry into maternal deaths reported that hypertension is now the main direct cause of maternal death. ${ }^{3}$ There is an increased incidence of abruptio placentae in patients with chronic hypertension. The incidence increases with increasing severity of hypertension and again if superimposed pre-eclampsia occurs. ${ }^{4}$

Hypertensive patients in their first pregnancy face the risk of additional pre-eclampsia. At term, up to 1,392 out of 11,812 , that is, $12 \%$ of singleton pregnancies are complicated by additional hypertension, this figure comprised $19 \%$ of primigravida and $6 \%$ of parous women. ${ }^{5}$ Multiple pregnancies and advanced maternal age increase the risk. ${ }^{6}$ Non-proteinuric hypertension seems to carry virtually no risk to the fetus ${ }^{7}$ but $25-30 \%$ of women with hypertension prior to pregnancy will develop proteinuria before term. ${ }^{8}$

\section{Chronic renal disease and other causes of hypertension}

Do the patients have a remediable cause for their hypertension? The question is pressing as the outcome of any pregnancy may be adversely

Correspondence: R.D.G. Tunbridge, M.D., F.R.C.P.

Received: 31 March 1994 affected by failure to find certain causes of hypertension. The search is for renal disease, renal artery stenosis, coarctation of the aorta, phaeo- $\bigcirc$ chromocytoma and Conn's syndrome, and an understanding of the mechanisms of secondary hypertension is helpful. ${ }^{9}$

Women who undertake pregnancy with a primary renal disease, most commonly glomerulo- $\triangle$ nephritis or reflux nephropathy, have a higher risk $\vec{z}$ of adverse fetal and maternal outcomes. ${ }^{10}$ In patients after renal transplantation with impaired $\stackrel{\Phi}{工}$ renal function, the perinatal mortality rate was doubled compared with transplant recipients with $\mathbb{\mathscr { }}$ normal renal function. Six out of 18 transplami $\vec{\oplus}$ patients with impaired renal function showed fur ther deterioration in renal function after preg. nancy. ${ }^{11}$

The natural history of patients with autosomal dominant polycystic disease revealed that women who had three or more pregnancies showed worse renal function in later life. ${ }^{12}$ No irreversible deterioration in renal function was reported in 26 pregnancies in 16 patients with pre-existing lupus nephritis, although the risk of obstetric and fetal complications was higher, especially in hypertensive pregnancies. ${ }^{13}$

Finding renal disease will warrant nephrological assessment. Remediable causes of impaired renal function should be treated prior to conception. Missing obstructive uropathy as a cause of hypertension and renal impairment in pregnancy remains a hazard. ${ }^{14}$

The prognosis for the mother will be that of the $\frac{D}{0}$ underlying renal disease. The fetal outcome in mothers with known renal disease but normal renal $N$ function will be indicated by the degree of $N$ associated hypertension, the development of proteinuria and the risks of additional pre-eclampsia.

\section{Age and diabetes}

The relation between maternal age and mortality from pregnancy hypertension showed a jump from 17.1 per million aged $30-34$, to 36.0 per million 
aged 35-39 and to 40.7 for the $40+$ age group. Yet, because of smaller numbers in the $>35$ age group, $86 \%$ of the hypertension-related deaths were in the under 35 age group. ${ }^{15}$

Both hypertension and diabetes are major factors in the excess morbidity and mortality associated with childbearing in women over $40 .^{16}$ Even patients with gestational diabetes showed an increased frequency of chronic hypertension, pregnancy-induced hypertension and pre-eclampsia, compared with 327 women with normal glucose tolerance at $28-32$ weeks of gestation. ${ }^{17}$ In patients with both diabetes and hypertension in pregnancy there is an increased risk for developing retinopathic complications. ${ }^{18}$

\section{Teratogenic risks}

Preconception counselling provides the opportunity of stopping anti-hypertensive medication before conception and thereby avoiding teratogenic effects. Of currently used anti-hypertensives, angiotensin converting (ACE) inhibitors cause concern. ${ }^{19}$ One study showed adverse effects on fetal outcome in two of 19 newborns whose mothers were exposed to ACE inhibitors. This indicates that the absolute risk may be high. ${ }^{20} \mathrm{~A}$ further report on three infants strongly suggested that ACE inhibitors are fetotoxic. ${ }^{21}$ It was proposed that the primary mechanism by which ACE inhibitors affect development of the fetal kidney is through decreased renal blood flow. ${ }^{22}$ ACE inhibitors have been associated with fetal growth retardation, neonatal respiratory failure and possible fetal deaths. ${ }^{23}$

Tailing off medication in well-controlled hypertensives is relatively easy as it often takes several months and sometimes up to a year before blood pressure returns to unacceptable levels. If conception is achieved during this period the fall in blood pressure which occurs in the first 16 weeks of pregnancy counteracts the hypertension. Half of the patients who have chronic hypertension during pregnancy can be expected to have normal blood pressures during the second trimester. Women whose blood pressure was previously unknown but who become hypertensive during the first 20 weeks of pregnancy are more likely to have underlying chronic hypertension. ${ }^{24}$

\section{Monitoring in pregnancy}

If the patient attends for antenatal care then her blood pressure will be monitored. Obstetricians will recognize the increased risk of hypertension associated with twin pregnancies, and complete or even partial hydatidiform mole. ${ }^{25}$ Unfortunately, it is likely that blood pressure will be casually recorded as evidenced by $78 \%$ of blood pressure readings ending in $0 .^{26}$ Diastolic blood pressures are still recorded using both muffling (phase IV) and the disappearance of sounds (phase V) as the end point. Most clinical trials of hypertension in pregnancy have used phase IV. ${ }^{24}$ There remains an urgent need for international consensus on how to measure the blood pressure accurately in pregnancy. ${ }^{27}$ This is unfortunate as precise recordings are as good a predictor of pre-eclampsia as any measure yet devised.

Ambulatory blood pressure monitoring in pregnancy demonstrates lower blood pressures when the patient is away from the medical centre. The same pattern is found in non-pregnancy hypertensives and the difficulties in comparing these measurements with traditional blood pressure readings remain unresolved. ${ }^{28}$

Because antenatal care will include blood pressure monitoring, it should be unnecessary for patients to attend medical outpatients additionally. The well-structured care provided by antenatal services will include monitoring of fetal growth and maternal renal function. Both low and high systolic and diastolic pressures are associated with intrauterine growth retardation and preterm delivery. ${ }^{29}$ Mild to moderate hypertension carries little risk to the mother or fetus. The risk is in it progressing to severe hypertension $(>160 / 100) \mathrm{mmHg}$ and preeclampsia, hence the need to monitor blood pressure carefully during pregnancy. All primigravida and women with known hypertension should have their blood pressure measured and urine checked for protein fortnightly from 24 weeks and then weekly as term approaches. ${ }^{30}$

\section{Proteinuria}

The detection and quantification of proteinuria remains a useful monitor of early renal changes and acts as an indicator of pregnancy outcome. ${ }^{31}$ Protein excretion is best estimated from 24 hour specimens rather than from 8 hour collections. ${ }^{32}$ Dipstick urinalysis showed a false-negative rate of $7 \%$ even in the presence of $100 \mathrm{mg} / \mathrm{dl}$ and cannot be totally relied upon either to detect or exclude the presence of proteinuria in pregnant women. ${ }^{33}$

In a study of renal disease, proteinuria and pregnancy outcome in 53 women, protein excretion of more than $500 \mathrm{mg} /$ day was associated with renal insufficiency in $62 \%$ and chronic hypertension in $40 \% ; 45 \%$ of infants were delivered pre-term and $23 \%$ had growth retardation; $62 \%$ developed clinical evidence compatible with superimposed pre-eclampsia; this figure rose to $100 \%$ if there was associated chronic hypertension. ${ }^{34}$ The management and pregnancy outcomes of 42 women with 
pre-eclampsia and proteinuria of greater or equal to $5 \mathrm{~g} / 24$ hours showed that $83 \%$ were delivered by caesarean section; $91 \%$ of these sections were delivered urgently before the onset of labour; perinatal mortality was high but only one mother had significant proteinuria 3 months after delivery. ${ }^{35}$

Diabetic patients developing proteinuria in the range $190-499 \mathrm{mg} /$ day before 20 week's gestation identified a group with a subsequent $31 \%$ rate of pre-eclampsia, with protein excretion above $500 \mathrm{mg} /$ day, the rate rose to $38 \%$. If the patients in addition had chronic hypertension, the rates rose to $50 \%$ and $58 \%$, respectively. ${ }^{36}$ In diabetic nephropathy control of hypertension is known to reduce protein excretion. Early diabetic nephropathy is associated with an increase in glomerular filtration rate similar to that found in early pregnancy, in subjects with pre-eclampsia this rise was absent. ${ }^{37}$

The use of atenolol in 100 women who developed hypertension in late pregnancy was associated with a reduction in proteinuria. ${ }^{38}$ When labetalol was used in 57 pregnant women with diastolic pressure greater than $90 \mathrm{mmHg}$, the degree of proteinuria was no different from the control group. ${ }^{39}$ A double-blind controlled study of labetalol involving 144 women with mild to moderate pregnancyinduced hypertension did show a reduced incidence of proteinuria but no improvement in indices of clinical outcome. ${ }^{40}$

\section{Uric acid levels}

Uric acid levels show diurnal variation. ${ }^{41}$ Sustained elevations are another marker of impaired renal function and hence are associated with a poor prognosis. ${ }^{42}$ Elevated uric acid levels in conjunction with substantial proteinuria can be used as a marker for superimposed pre-eclampsia in women already taking anti-hypertensive medication. ${ }^{43}$

\section{Bed rest}

The tradition of bed rest for the patient with hypertension in pregnancy started in the $1950 \mathrm{~s}^{44}$ and persists despite reports of it being ineffective. Recent studies continue to show no improvements in fetal growth or neonatal morbidity as a result of bed rest, nor did it prevent the development of proteinuria. ${ }^{45}$ Because of the cost and inconvenience of this traditional management, the National Health Service Research and Development department might wish to address the issue.

Improvements in the domiciliary midwifery services now provide better facilities for monitoring hypertensive patients outside hospital. Another alternative is the use of day hospitals. ${ }^{46,47}$ Studies of day hospital care have only identified relatively small cost savings ${ }^{48}$ but long experience in Glasgow $\mathbb{\mathbb { D }}$ has shown day care to be acceptable to women. ${ }^{49} \mathrm{C}$

Home monitoring means that recordings can be made which do not reflect the stress of a hospital $\stackrel{5}{\rightarrow}$ visit, ${ }^{50}$ but an attempt to measure anxiety levels between home and hospital monitoring showed no differences. ${ }^{51}$ Home monitoring of blood pressures requires common protocols of management to be agreed between the hospital and community services. ${ }^{52}$ Such protocols must stress that the development of proteinuric pre-eclampsia with symptoms warrants emergency admission to hospital. ${ }^{30}$

\section{Pre-eclampsia and aspirin}

Does aspirin therapy reduce the risk of additional pre-eclampsia? Studies on the action of aspirin on platelet reactivity and prostaglandin production have given a theoretical basis for testing aspirin use $^{53}$ and small studies on selected high-risk patients have been interpreted to show benefit. ${ }^{54}$ These promising early studies stimulated larger trials. In nulliparous women, $60 \mathrm{mg}$ aspirin was given from 24 weeks once drug compliance had proved satisfactory. A positive outcome with $5 / 302 \stackrel{\Phi}{\subseteq}$ $(1.7 \%)$ in the aspirin group developing pre $\vec{\bullet}$ eclampsia compared with $17 / 302(5.6 \%)$ in the placebo group $(P=0.0009)$ was reported. ${ }^{55}$ How ever, in an open study in which $50 \mathrm{mg}$ of aspirin was given daily to 583 women judged to be at moderate risk of pre-eclampsia or intrauterine growth disorder gave little support for its use. ${ }^{56}$ Use of aspirin after the diagnosis of pre-eclampsia is ineffective. $^{57}$

These uncertainties led to the National Institutes of Health Study ${ }^{58}$ of 3,135 nulliparous women, in which, 1,570 women were given aspirin $60 \mathrm{mg}$ per day starting from 13 to 26 weeks gestation. The incidence of pre-eclampsia was $4.6 \%$ in the aspirin group and $6.3 \%$ in the placebo group (relative risk $0.7 ; 95 \%$ confidence intervals 0.6 to 1 ). The incidence of gestational hypertension was $6.7 \%$ and $5.9 \%$, respectively. There was no significant difference in birth weight, fetal growth retardation, postpartum haemorrhage or neonatal bleeding problems. Eleven women in the aspirin group had abruptio placentae compared with two in the $N$ placebo group $(P=0.01)$. Subgroup analysis showed that pre-eclampsia occurred more commonly in those with initial systolic pressure $120-134 \mathrm{mmHg}$. Aspirin in this group reduced pre-eclampsia from $11.9 \%$ to $5.6 \%(P=0.01){ }^{58} \circ$ This more powerful trial gives little support for $\mathbb{D}$ unselective aspirin use and is in line with earlier : conclusions that its use should be selective. ${ }^{59}$

The recently published Collaborative Low-dose Aspirin Study in Pregnancy (CLASP) trial had 


\section{Key points}

Hypertension is the main direct cause of maternal death, the risk doubles in the over-35 age group.

Non-proteinuric hypertension seems to carry virtually no risk to the fetus.

Women who undertake pregnancy with a primary renal disease have a higher risk of adverse fetal and maternal outcomes.

Where possible stop anti-hypertensives (especially ACE inhibitors) prior to conception.

Measure blood pressure to the nearest $2 \mathrm{mmHg}$. Check for proteinuria fortnightly from 24 weeks.

Aspirin prophylaxis was not shown to be of benefit in large studies.

Anti-hypertensive therapy with methyl dopa is safe and has been associated with reduced mid-term fetal loss, but has no effect on maternal outcome.

Beta-blocker therapy does reduce the risk of developing severe hypertension but not of developing preeclampsia.

Anti-hypertensive therapy should be reviewed within 2 weeks of delivery.

Both prenatal and postnatal counselling should be offered.
3,467 subjects in a trial of prophylactic aspirin therapy. ${ }^{60}$ This group included at risk patients selected on the basis of chronic hypertension $(n=933)$, renal disease $(n=223)$, diabetes $(n=$ 129), maternal age, family history or multiple pregnancy. In the same group were women with a history of pre-eclampsia or intrauterine growth retardation. Using $60 \mathrm{mg}$ aspirin from as early as 12 weeks, the conclusion was that this therapy would prevent proteinuric pre-eclampsia in about one women out of every 100 treated. The reduction in deliveries before 37 weeks estimated gestation would be 2.5 per 100 women treated. There was no increase in maternal or fetal bleeding disorders in women on aspirin but they did receive more post-delivery blood transfusions. There was a trend towards progressively greater reductions in proteinuric pre-eclampsia the more pre-term the delivery.

\section{Anti-hypertensive therapy during pregnancy}

Patients with hypertension at the start of pregnancy will tend to show increasing levels of blood pressure after the 16 th week. The rate of rise cannot be predicted but needs monitoring to determine the optimal point for initiating anti-hypertensive therapy. Unfortunately, despite the high prevalence of hypertension in pregnancy, there remain few powerful controlled studies of the results of anti-hypertensive treatment in pregnancy. The bulk of the evidence relates to methyl dopa. This shows that initiating methyl dopa therapy once blood pressure levels exceed $170 / 110 \mathrm{mmHg}$ in early pregnancy reduced mid-term fetal loss by four out of 242 pregnancies but had no effect on maternal outcome. ${ }^{42}$ The fetal outcome, and subsequent growth and development until aged 7 has been reported. ${ }^{61}$

Beta-blockers provide an alternative to methyl dopa. The best studied of these is atenolol. Concern has been expressed about the adverse effects of beta-blockers on fetal outcome, especially in uncontrolled studies. A small study compared the haemodynamic effects of atenolol in 13 patients with pindolol in $16 .^{62}$ The finding of reduced placental weight in the atenolol group has been given undue emphasis. Small uncontrolled drug studies claiming adverse fetal effects are still being published. ${ }^{63}$ Controlled studies in late pregnancy have shown improved blood pressure control that resulted in reduced admission to hospital and no detected long-term adverse effects on fetal outcome. ${ }^{38}$ More recent studies in which therapy was started early in pregnancy were reported as indicating an increased risk to the fetus but the study did not reach its intended size and the adverse effects are interpreted on the basis of two adverse events from a group of 15 pregnant women on atenolol compared with a similar-sized control group. ${ }^{64}$ Meta-analysis of 11 trials involving 1,200 women with moderate hypertension in pregnancy indicated that beta-blocker therapy reduced the risk of developing severe hypertension but not of developing pre-eclampsia. ${ }^{65}$

Studies of other hypotensive drugs for the treatment of hypertension in pregnancy again suffer a lack of power and absence of long-term follow-up data. A recent study of 100 patients treated with nifedipine (unlicensed for use in pregnancy in the United Kingdom) showed a reduction in maternal blood pressure but no improvement in perinatal outcome compared with 100 patients treated with bed rest. ${ }^{65}$ Ultrasound studies of the effects of hypotensive drugs on blood flow in uterine, umbilical and fetal blood pressures are being used to detect alterations in blood flow that might be considered detrimental..$^{67,68}$

Hypotensive drug pharmacokinetics may be altered in pregnancy. Studies on nifedipine showed reduced terminal elimination half life, which indicates that it would need to be administered at shorter intervals in pregnant than in the nonpregnant women. ${ }^{69}$ Peak plasma metoprolol concentrations were four times higher after the same oral dose in the non-pregnant state. ${ }^{70}$ Studies of the 
transplacental transfer of hypotensive drugs with, for example, isradipine showed that its concentration is considerably lower in fetal compared with maternal plasma. ${ }^{71}$

The scope of anti-hypertensive therapy in pregnancy is therefore limited to protecting the mother from the dangers of severe hypertension, particularly cerebral haemorrhage in the context of pre-eclampsia. ${ }^{72}$ Current UK practice favours oral labetalol $(35 \%)$, oral methyl dopa $(23 \%)$ and parenteral hydralazine $(29 \%){ }^{73}$ although oral nifedipine may have some advantages. ${ }^{7}$ Women with mild hypertension in pregnancy, no hypertension before pregnancy and who do not develop proteinuria can with close supervision be treated conservatively. ${ }^{75}$

In established hypertensives in early pregnancy it is realistic to expect the patient to run higher blood pressure levels than the accepted $140 / 90 \mathrm{mmHg}$. Setting a higher target reduces anxiety in both patients and their carers. Obstetricians rightly remain concerned about the risk of eclampsia and will have to make the difficult clinical decision on when to intervene. One definition of pregnancyinduced hypertension is a rise of $>30 \mathrm{mmHg}$ systolic or $>15 \mathrm{mmHg}$ diastolic compared with readings taken early in pregnancy. ${ }^{76}$

In severe pre-eclampsia prior to delivery, American practice has relied on magnesium sulphate, ${ }^{77}$ whereas UK or New Zealand practice ${ }^{73}$ has deployed i.m./i.v. hydralazine or short-term use of sodium nitroprusside both backed by phenytoin therapy. Experimentation into the mode of action of magnesium sulphate has shown that it acts as a local vasodilator of the vascular bed distal to the maternal middle cerebral arteries. ${ }^{78}$ Hydralazine given by either constant infusion or intermittent injection can accumulate causing hypotension. Bolus doses of from 5 to $10 \mathrm{mg}$ should not be given more frequently than 20-30 minutes. ${ }^{72}$ The use of these agents however remains limited to controlling blood pressure over the immediate pre- and postpartum period.

Abnormalities of platelet function are a wellrecognized complication of severe pre-eclampsia. ${ }^{79}$ A study of severe pre-eclampsia occurring between 26 and 32 weeks in 67 pre-term pregnancies showed this to be associated with chronic hypertension and renal disease, and adverse effects on fetal outcome. ${ }^{80}$

Occurrence of the HELLP syndrome (acute haemolysis, abnormal liver function and thrombocytopenia ${ }^{81}$ ) is associated with high maternal mortality, a greater incidence of eclamptic crisis, severe hypertension, higher protein excretion and episodes of acute renal failure. ${ }^{82}$ Not surprisingly a case can be made for managing such patients in an intensive care unit. ${ }^{83}$ Fortunately blood pressure normally settles rapidly after delivery but can occur for the first time postpartum. ${ }^{84}$ Despite being in $\frac{2}{3}$ common use it is sometimes forgotten that rebound $\stackrel{\mathbb{Q}}{\propto}$ hypertension occurs on methyl dopa withdrawal. A $c$ regime of gradual withdrawal spread over 4 days is $\vec{F}$ recommended. Methyl dopa is not expressed in $\stackrel{5}{+}$ significant quantities in breast milk. Atenolol withdrawal does not precipitate rebound hypertension to the same degree. Again its concentration in $\frac{\rho}{\vec{D}}$

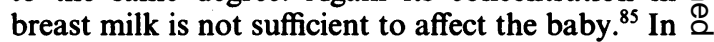
patients with extensive oedema it is tempting to introduce a diuretic at this stage. These drugs are $\vec{\circ}$ likely to interfere with lactation and should therefore be avoided if the mother wishes to breast feed. ${ }^{86}$

Hypertension may recur as a problem around the time of planned discharge. Unless related to drug withdrawal or unrecognized changes in renal function, the blood pressure elevation may be no more than an indicator of stresses placed on the mother at this vulnerable time.

The sixth week postnatal visit is too long a delay before monitoring the changes in blood pressure after delivery. It is unkind or even dangerous to render the mother hypotensive in this period. The midwife will record blood pressure for a 10-day period. The rate of decline in blood pressure and the rate at which anti-hypertensive medication have to be withdrawn can be variable. An assese ment around 2 weeks after delivery is necessary an $\bar{A}$. this may have to be repeated before the tradition 6 week postnatal visit. One definition of chronic hypertension in pregnancy requires the patient to remain hypertensive $\mathbf{4 2}$ days after delivery. ${ }^{87}$

In the longer term, certain patients' blood pressure may take as long as 6 months or even a year to return to pre-pregnancy levels. The interrelation between weight and blood pressure is important, an increase in weight of $6 \mathrm{~kg}$ is associated with a $9 \mathrm{mmHg}$ increase in diastolic pressure. The speed with which proteinuria declines can be as varied as that of the blood pressure. It is realistic to wait for 6 months before making a final quantification of proteinuria and considering nephrological referral if proteinuria remains above $300 \mathrm{mg} / 24$ hours.

\section{Postnatal counselling}

During the follow-up period, further counselling will be needed. Patients are likely to have received contraceptive advice at their postnatal visit. An absolute ban on the use of combined oral contraceptive medication for women who have a history of hypertension is often given. These $\varrho$ patients are likely to have their blood pressure monitored and, if they request oral contraceptives, can be given a trial course so that the effects on their blood pressure can be assessed. Low-dose oral contraceptives can usually be used safely in non- 
smoking younger hypertensives whose blood pressure is well controlled. ${ }^{88}$ Women with diabetes and hypertension should not use the combined pill. ${ }^{89}$ Older women, smokers and patients with poorly controlled blood pressure can be given progestin only pills or advised on non-pharmacological alternatives. ${ }^{90}$

Women will also want to know the risk of recurrence of hypertension in subsequent pregnancies. Careful collection of the evidence has shown that hypertension is less likely to be a problem in the second or third pregnancies. A pattern of hypertension increasing in severity with each successive pregnancy, however, is a pointer to severe hypertensive problems both in pregnancy and in later life. The subsequent history of 223 women who had eclampsia is described in a review by Sibai. ${ }^{91}$ From a total of 366 subsequent pregnancies $1.9 \%$ had eclampsia. Pregnancy outcomes were worse in those women who had experienced eclampsia before 37 weeks' gestation. The question again as to whether an underlying cause of hypertension in the first pregnancy was missed needs to be answered before giving advice concerning future pregnancies. The conundrum of low birth weight and higher placental weight at term as a marker for the development of hypertension in later life independent of maternal blood pressure during pregnancy as described by Barker remains topical. ${ }^{92,93}$

The wheel has returned full circle to counselling. The process needs to be undertaken early or, as my obstetric colleagues know, you will be confronted with a second pregnancy before having fully evaluated the effects of the first. Although maternal hypertension has adverse effects on perinatal outcome, a small study of 37 children showed that most had normal growth and development in childhood..$^{94}$ Recurrent mild hypertension in successive pregnancies remains a marker for the development of chronic hypertension in these women in later life. ${ }^{95}$ The pregnancy outcome of 13 women who had chronic hypertension before developing eclampsia showed an alarmingly high risk of severe pre-eclampsia and poor fetal outcome in subsequent pregnancy. ${ }^{91}$ The management of hypertension in women should include preconception counselling, the identification of high-risk pregnancies and their continuous monitoring right through to postnatal reassessment.

\section{References}

1. Church J. (ed.) Social Trends, Vol. 24. Central Statistical Office, London, 1994.

2. Davey, D.A. \& MacGillivary, I. The classification and definition of the hypertensive disorders of pregnancy. Am J Obstet Gynaecol 1988, 158: 982-988.

3. Department of Health. Reports on Confidential Enquiries into Maternal Deaths in England and Wales 1988-1990. HMSO, London, 1994.

4. Dunlop, J.C.H. Chronic hypertension and perinatal mortality. Proc $R$ Soc Med 1966, 59: 838-841.

5. Andrews, W.W., Cox, S.M., Sherman, M.L. \& Leveno, K.J. Maternal and perinatal effects of hypertension at term. $J$ Reprod Med 1992, 37: 73-76.

6. Savitz, D.A. \& Zhang, J. Pregnancy-induced hypertension in North Carolina, 1988 and 1989. Am J Public Health 1992, 82: 675-679.

7. Banfield, P.J., O'Hanlon, M., Chapple, J. \& Mugford, M. Second Report of the North West Thames Maternity Statistics 1990. NWTRHA, London.

8. Walker, J.J. Day care obstetrics (editorial). Br J Hosp Med 1993, 50: 225-226.

9. Streeten, D.H. \& Anderson, G.H. Secondary hypertension. An overview of its causes and management. Drugs 1992, 43: 805-819.

10. Brown, M.A. \& Whitworth, J.A. The kidney in hypertensive pregnancies - victim and villain. Am J Kidney Dis 1992, 20: 427-442.

11. Cararach, V., Carmona, F., Monleon, F.J. \& Andreu, J. Pregancy after renal transplantation: 25 years experience in Spain. Br J Obstet Gynaecol 1993, 100: 122-125.

12. Gabow, P.A., Johnson, A.M., Kaehny, W.D. et al. Factors affecting the progression of renal disease in autosomaldominant polycystic kidney disease. Kidney Int 1992, 41: $1311-1319$.

13. Julkunen, H., Kaaja, R., Palosuo, T., Gronhagen-Riska, C.\& Teramo, K. Pregnancy in lupus nephropathy. Acta Obstet Gynecol Scand 1992, 72: 258-263.
14. Satin, A.J., Seiken, G.L. \& Cunningham, F.G. Reversible hypertension in pregnancy caused by obstructive uropathy. Obstet Gynecol 1993, 81: 823-825.

15. Hall, M. \& Campbell, D. Cost-effectiveness of presen programs for detection of asymptomatic hypertension in relation to the severity of hypertension and proteinuric hypertension. Int J Technol Assess Health Care 1992, 8 (Supp 1): $75-81$.

16. O'Reilly-Green, C. \& Cohen, W.R. Pregnancy in women aged 40 and older. Obstet Gynecol Clin North Am 1993, 20: 313-331.

17. Suhonen, L. \& Teramo, K. Hypertension and pre-eclampsia in women with gestational glucose intolerance. Acta Obstet Gynecol Scand 1993, 72: 269-272.

18. Rosenn, B., Miodovnik, M., Kranias, G. et al. Progression of diabetic retinopathy in pregnancy: association with hypertension in pregnancy. Am J Obstet Gynecol 1992, 166: 1214-1218.

19. Hanssens, M., Keirse, M.J.N.C., Vankelecom, F. \& Van Assche, A. Fetal and neonatal effects of treatment with angiotensin converting enzyme inhibitors in pregnancy. Obstet Gynaecol 1991, 78: 128-135.

20. Piper, J.M., Ray, W.A. \& Rosa, F.W. Pregnancy outcome following exposure to angiotensin-converting enzyme inhibitors. Obstet Gynecol 1992, 80: 429-432.

21. Pryde, P.G., Sedman, A.B., Nugent, C.E. \& Barr, M., Jr. Angiotensin-converting enzyme inhibitor fetopathy. $J \mathrm{Am}$ Soc Nephrol 1993, 3: 1575-1582.

22. Martin, R.A., Jones, K.L., Mendoza, A., Barr, M., Jr \& Benirschke, $K$. Effect of ACE inhibition on the fetal kidney: decreased renal blood flow. Teratology 1992, 46: 317-321.

23. Executive summary. Management of hypertension in pregnancy. Med J Australia 1993, 158: 700-702.

24. Sibai, B. Diagnosis and management of chronic hypertension in pregnancy. Obstet Gynaecol 1991, 78: 451-461. 
25. Cox, S.M. \& Klein, V.R. Partial molar pregnancy associated with severe pregnancy-induced hypertension. J Perinatol 1993, 13: 103-106.

26. Wen, S.W., Kramer, M.S., Hoey, J., Hanly, J.A. \& Usher, R.H. Terminal digit preference, random error, and bias in routine clinical measurement of blood pressure. J Clin Epidemiol 1993, 46: 1187-1193.

27. Brown, M.A. \& Simpson, J.M. Diversity of blood pressure recording during pregnancy: implications for the hypertensive disorders. Br Med J 1992, 156: 306-308.

28. Rayburn, W.F. \& Zuspan; F.P. Portable blood pressure monitoring for borderline or mild hypertension during pregnancy. Clin Obstet Gynecol 1992, 35: 395-401.

29. Goldenberg, R.L., Cliver, S.P., Cutter, G.R., Davis, R.O., Hoffman, H.J. \& Wen, S.W. Blood pressure, growth retardation, and preterm delivery. Int J Technol Assess Health Care 1992, 8 (Suppl 1): 82-90.

30. Redman, C.W.G. \& Roberts, J.M. Management of preeclampsia. Lancet 1993, 341: 1451-1454.

31. Sibai, B.M. \& Anderson, G.D. Pregnancy outcome of severe hypertension in first trimester. Obstet Gynecol 1986, 67: 517-522.

32. Lindow, S.W. \& Davey, D.A. The variability of urinary protein and creatinine excretion in patients with gestational proteinuric hypertension. Br J Obstet Gynaecol 1992, 99: 869-872.

33. Kuo, V.S., Koumantakis, G. \& Gallery, E.D. Proteinuria and its assessment in normal and hypertensive pregnancy. $A m \mathrm{~J}$ Obstet Gynecol 1992, 167: 723-728.

34. Stettler, R.W. \& Cunningham, F.G. Natural history of chronic proteinuria complicating pregnancy. Am J Obstet Gynecol 1992, 167: 1219-1224.

35. Chua, S. \& Redman, C.W. Prognosis for pre-eclampsia complicated by $5 \mathrm{~g}$ or more of proteinuria in 24 hours. Eur $J$ Obstet Gynecol Reprod Biol 1992, 43: 9-12.

36. Combs, C.A., Rosenn, B., Kitzmiller, J.L., Khoury, J.C., Wheeler, B.C. \& Miodovnik, M. Early-pregnancy proteinuria in diabetes related to preeclampsia. Obstet Gynecol 1993, 82: 802-807.

37. Krutzen, E., Olofsson, P., Back, S.E. \& Nilsson-Ehle, P. Glomerular filtration rate in pregnancy: a study in normal subjects and in patients with hypertension, preeclampsia and diabetes. Scand J Clin Lab Invest 1992, 52: 387-392.

38. Rubin, P.C., Butters, L., Clark, D.M. et al. Placebocontrolled trial of atenolol in treatment of pregnancyassociated hypertension. Lancet 1983, i: 431-434.

39. Cruickshank, D.J., Robertson, A.A., Campbell, D.M. \& MacGillivray, I. Does labetalol influence the development of proteinuria in pregnancy hypertension? A randomised controlled study. Eur J Obstet Gynecol Reprod Biol 1992, 45: 47-51.

40. Pickles, C.J., Broughton-Pipkin, F. \& Symonds, E.M. A randomised placebo controlled trial of labetalol in the treatment of mild to moderate pregnancy induced hypertension. Br J Obstet Gynaecol 1992, 99: 964-968.

41. Devgun, M.S. \& Dhillon, H.S. Importance of diurnal variations on clinical value and interpretation of serum urate measurements. J Clin Pathol 1992, 45: 110-113.

42. Redman, C.W.E., Beilin, L., Bonnar, J. et al. Fetal outcome in trial of antihypertensive treatment in pregnancy. Lancet 1976, ii: 753-756.

43. Varma, T.R. Serum uric acid levels as an index of fetal prognosis in pregnancies complicated by pre-existing hypertension and pre-eclampsia of pregnancy. Int J Gynaecol Obstet 1982, 1982: 401-408.

44. Hamlin, R.H.J. The prevention of eclampsia and preeclampsia. Lancet 1952, i: 64-68.

45. Crowther, C.A., Bouwmeester, A.M. \& Ashurst, H.M. Does admission to hospital for bed rest prevent disease progression or improve fetal outcome in pregnancy complicated by non-proteinuric hypertension? Br J Obstet Gynaecol 1992, 99: 13-17.
46. Soothill, P.W., Ajayi, R., Campbell, S. et al. Effect of fetal surveillance unit on admission of antenatal patients to hospital. Br Med J 1991, 303: 269-271.

47. Tuffnell, D.J., Lilford, R.J., Buchan, P.C. et al. Randomised controlled trial of day care for hypertension in pregnancy. Lancet 1992, 339: 224-227.

48. Twaddle, S. \& Harper, V. Day care and pregnancy hypertension (letter; comment). Lancet 1992, 339: 8131-814.

49. Twaddle, S. \& Harper, V. An economic evaluation of daycare in the management of hypertension in pregnancy. $\mathrm{Br} J$ Obste Gynaecol 1992, 99: 459-463.

50. Kennedy, S. Monitoring hypertension in pregnancy. Prof Nurse 1991, 6: 566-568.

51. Cartwright, W., Dalton, K.J., Swindells, H., Rushant, S. \& Mooney, P. Objective measurement of anxiety in hypertensive pregnant women managed in hospital and in the community. Br J Obstet Gynaecol 1992, 99: 182-185.

52. Ratten, G.J. \& McDonald, L. Organization and early results of a shared antenatal care programme. Aust $N$ Zealand $J$ Obstet Gynaecol 1992, 32: 296-300.

53. Louden, K.A., Broughton-Pipkin, F., Symonds, E.M. et al. A randomized placebo-controlled study of the effect of low dose aspirin on platelet reactivity and serum thromboxane $B 2$ production in non-pregnant women, in normal pregnancy, and in gestational hypertension. Br J Obstet Gynaecol 1992, 99: $371-376$.

54. Wallenburg, H.C., Dekker, G.A., Makovitz, J.W. \& Rotmans, P. Low dose aspirin prevents pregnancy-induced hypertension and pre-eclampsia in angiotensin-sensitive primigravidae. Lancet 1986 , i: $1-3$.

55. Hauth, J.C., Goldenberg, R.L., Parker, C.R., Jr et al. Low-dose aspirin therapy to prevent preeclampsia. $\mathrm{Am} J$ Obstet Gynceol 1993, 168: 1083-1091 (discussion 10911093).

56. Italian Study of Aspirin in Pregnancy. Low-dose aspirin i prevention and treatment of intrauterine growth retardatio and pregnancy induced hypertension. Lancet 1993, 341 $396-400$.

57. Niebyl, J.R. Drug therapy during pregnancy. Curr Opin Obstet Gynecol 1992, 4: 43-47.

58. Sibai, B.M., Caritis, S.N., Thom, E. et al. Prevention of pre-eclampsia with low-dose aspirin in healthy, nulliparous pregnant women. The National Institute of Child Health and Human Development Network of Maternal-Fetal Medicine Units. $N$ Engl J Med 1993, 329: 1213-1218.

59. Schiff, E. \& Mashiach, S. The use of low dose aspirin in pregnancy. Am J Reprod Immunol 1992, 28: 153-156.

60. CLASP. A randomised trial of low-dose aspirin for the prevention and treatment of pre-eclampsia among 9364 pregnant women. Lancet 1994, 343: 619-629.

61. Cockburn, J., Moar, V.A. \& Ounsted, M. Final report of study on hypertension during pregnancy: the effects of specific treatment on the growth and development of the children. Lancet 1982, i: 647-649.

62. Montan, S., Ingemarsson, I., Marsal, K. \& Sjoberg, N.O Randomised controlled trial of atenolol and pindolol in human pregnancy: effects on fetal haemodynamics. Br Med 1992, 304: 946-949.

63. Kaaja, R., Hiilesmaa, V., Holma, K. \& Jarvenpaa, A.L Maternal anti-hypertensive therapy with beta-blockers associated with poor outcome in very-low birthweigh infants. Int J Gynaecol Obstet 1992, 38: 195-199.

64. Butters, L., Kennedy, S. \& Rubin, P.C. Atenolol in essential hypertension during pregnancy. $\mathrm{Br}$ Med $J$ 1990, 301 587-589.

65. Collins, R. \& Duley, L. Beta-blockers vs methyl dopa in the treatment of pre-eclampsia. Oxford Database of Perinatal Trials Version 1.3. Disk issue 8. Autumn 1992. Record 3999. 
66. Sibai, B.M., Barton, J.R., Akl, S., Sarinoglu, C. \& Mercer, B.M. A randomized prospective comparison of nifedipine and bed rest versus bed rest alone in the management of preeclampsia remote from term. Am J Obstet Gynecol 1992, 167: 879-884.

67. Morgan, M.A., Silavin, S.L., Dormer, K.J., Fishburne, B.C. \& Fishburne, J.I., Jr. Effects of labetalol on uterine blood flow and cardiovascular hemodynamics in the hypertensive gravid baboon. Am J Obstet Gynecol 1993, 168: 1574-1579.

68. Montan, S., Anandakumar, C., Arulkumaran, S., Ingemarsson, I. \& Ratnam, S.S. Effects of methyldopa on uteroplacental and fetal hemodynamics in pregnancyinduced hypertension. Am J Obstet Gynecol 1993, 168: $152-156$

69. Prevost, R.R., Akl, S.A., Whybrew, W.D. \& Sibai, B.M. Oral nifedipine pharmacokinetics in pregnancy-induced hypertension. Pharmacotherapy 1992, 12: 174-177.

70. Hogstedt, S. \& Rane, A. Plasma concentration-effect relationship of metoprolol during and after pregnancy. Eur J Clin Pharmacol 1993, 44: 243-246.

71. Lunell, N.O., Bondesson, U., Grunewald, C., Ingemarsson, I., Nisell, H. \& Wide-Swensson, D. Transplacental passage of isradipine in the treatment of pregnancy-induced hypertension. Am J Hypertens 1993, 6: 110S-111S.

72. Kyle, P.M. \& Redman, C.W. Comparative risk-benefit assessment of drugs used in the management of hypertension in pregnancy. Drug Safety 1992, 7: 223-234.

73. Hutton, J.D., James, D.K., Stirrat, G.M., Douglas, K.A. \& Redman, C.W. Management of severe pre-eclampsia and eclampsia by UK consultants. Br J Ostet Gynaecol 1992, 99: $554-556$.

74. Fenakel, K., Fenakel, G., Appleman, Z., Lurie, S. \& Shoham, $Z$. Nifedipine in the treatment of severe pre-eclampsia. Obstet Gynaecol 1991, 77: 331-337.

75. Hjertberg, R., Belfrage, P. \& Hanson, U. Conservative treatment of mild and moderate hypertension in pregnancy. Acta Obstet Gynecol Scand 1992, 71: 439-446.

76. Working Group. National high blood pressure education programme working group report on high blood pressure in pregnancy. Am J Obstet Gynaecol 1990, 163: 1691-1712.

77. McCombs, J. Treatment of preeclampsia and eclampsia. Clin Pharm 1992, 11: 236-245.

78. Belfort, M.A., Saade, G.R. \& Moise, K.J., Jr. The effect of magnesium sulfate on maternal and fetal blood flow in pregnancy-induced hypertension. Acta Obstet Gynecol Scand 1993, 72: 526-530.
79. Redman, C.W., Bonnar, J. \& Beilin, L. Early platelet consumption in pre-eclampsia. Br Med J 1978, i: 467-469.

80. Banias, B.B., Devoe, L.D. \& Nolan, T.E. Severe preeclampsia in pre-term pregnancy between 26 and 32 weeks' gestation. Am J Perinatol 1992, 9: 357-360.

81. Weinstein, L. Syndrome of haemolysis, elevated liver enzymes and low platelet count: a severe consequence of hypotension in pregnancy. Obstet Gynaecol 1982, 142: 159-163.

82. Abroug, F., Boujdaria, R., Nouira, S. et al. HELLP syndrome: incidence and maternal-fetal outcome - a prospective study. Intens Care Med 1992, 18: 274-277.

83. Mourad, $O$. The intensive care management of severe pregnancy induced hypertension. Aust Crit Care 1992, 5: 20-23.

84. Rosenfeld, J.A. Hypertension occurring for the first time postpartum: was it preeclampsia? J Tenn Med Assoc 1992, 85: 465-466.

85. Diamond, J.M. Toxic Effects of atenolol consumed during breast feeding. $J$ Paediatr Child Health 1989, 115: 336-337.

86. White, W.B. Management of hypertension during lactation. Hypertension 1984, 6: 297-300.

87. Hughes, E.C. Obstetric-Gynaecological Terminology. F.A Davis, Philadelphia, 1982.

88. Speroff, L. \& Darney, P.D. (eds) A Clinical Guide for Contraception. Williams \& Wilkins, Baltimore, 1992.

89. Fraser, I.S. Contraceptive choice for women with 'risk factors'. Drug Safety 1993, 8: 271-279.

90. Sullivan, J.M. \& Lobo, R.A. Considerations for contraception in women with cardiovascular disorders. Am J Obstet Gynecol 1993, 168: 2006-2011.

91. Sibai, B.M., Sarinoglu, C. \& Mercer, B.M. Eclampsia. VII. Pregnancy outcome after eclampsia and long-term prognosis. Am J Obstet Gynecol 1992, 166: 1757-1761 (discussion 1761-1763).

92. Law, C.M., de-Swiet, M., Osmond, C. et al. Initiation of hypertension in utero and its amplification throughout life. Br Med J 1993, 306: 24-27.

93. Barker, D.J., Godfrey, K.M., Osmond, C. \& Bull, A. The relation of fetal length, ponderal index and head circumference to blood pressure and the risk of hypertension in adult life. Paediatr Perinat Epidemiol 1992, 6: 35-44.

94. Wilson, D.C., Harper, A., McClure, G., Halliday, H.L. \& Reid, M.M. Follow-up of children born to hypertensive mothers. Br J Clin Pract 1993, 47: 19-20.

95. Adams, E.M. MacGillivary, I. Long term effects of preeclampsia on the blood pressure. Lancet 1961, ii: 1373-1375. 